\title{
Tsafon
}

Revue d'études juives du Nord

$72 \mid 2016$

Juifs, Israéliens, dans la littérature française et israélienne

\section{Une promenade insolite à Varsovie}

\section{Izabella Zatorska}

\section{(2) OpenEdition \\ Journals}

Édition électronique

URL : https://journals.openedition.org/tsafon/503

DOI : $10.4000 /$ tsafon.503

ISSN : 2609-6420

Éditeur

Association Jean-Marie Delmaire

\section{Édition imprimée}

Date de publication : 1 décembre 2016

Pagination : 167-168

ISSN : 1149-6630

\section{Référence électronique}

Izabella Zatorska, « Une promenade insolite à Varsovie », Tsafon [En ligne], 72 | 2016, mis en ligne le 31 mai 2018, consulté le 28 juin 2021. URL : http://journals.openedition.org/tsafon/503 ; DOI : https:// doi.org/10.4000/tsafon.503 


\section{Une promenade insolite à Varsovie par Izabella Zatorska}

Le terrain de l'ancien petit ghetto et des environs offre au touriste une promenade insolite.

Certaines rues, comme Chłodna, sont pavées à l'ancienne, avec d'anciens rails de tram, des baraquements ou des pavillons mais aussi des vides et des terre-pleins, à la limite de Mirow et Czyste, et le tout au cœur de la capitale ! Aucun bus (une ligne à peine) n'y circule.

C'est un fragment du centre-ville appelé après la guerre le Far West (plutôt Wild West, en polonais). La Maison des Orphelins n'est pas la même qu'autrefois, rien ne ressemble à la façade d'antan, des résidences poussent de toute part et d'anciens HLM, clairsemés mais retapés, les boudent. Dans ce quartier, on trouve encore de petites placettes où des dames plutôt âgées passent des soirées à bavarder, comme en province !

À quelques carrefours, des vestiges du mur de ghetto sont marqués au sol, voire à la verticale: des photos accompagnées de légendes sont à découvrir dans un photoplasticon (il faut être grand pour y atteindre), ce dernier se trouve juste à l'endroit de la passerelle qui reliait les deux parties du ghetto.

Tout ce quartier, en dépit de tours ou de sièges de bureaux massifs, a l'air hanté, même si, à part les quelques squares, des bistros et des cafés, nombreux jusqu'à former des allées, par endroits, lui rendent une vie : des jeunes et/ou touristes les hantent, plus de fantômes. Quelques rues plus loin, les façades aveuglées d'immeubles vendus, quelques logements éclairés, même des fleurs aux fenêtres, le reste sombre... Parfois, ce sont des immeubles imposants, de vraies forteresses, comme à l'angle de Zlota et Zelazna. Mais au crépuscule leur aspect mort, incertain, se dessine encore plus inquiétant. Vont-ils tous disparaître ? Laisser la place à des résidences qui pullulent dans le quartier, lui donnant un caractère bien étranger pour les Varsoviens de souche.

Quelques rares maisons ont été bien retapées, très jolies, parfois, comme celle à l'angle de Chłodna et Wronia. Il y a même une ancienne horloge toute ronde et qui fonctionne, au-dessus de la pharmacie, à l'entresol !

Il se trouve donc encore une ville, peu connue, qui réunit les passés simple, composé, récent, au présent, voire au futur. Tout en donnant à respirer le climat de chaque époque, entre deux feux.

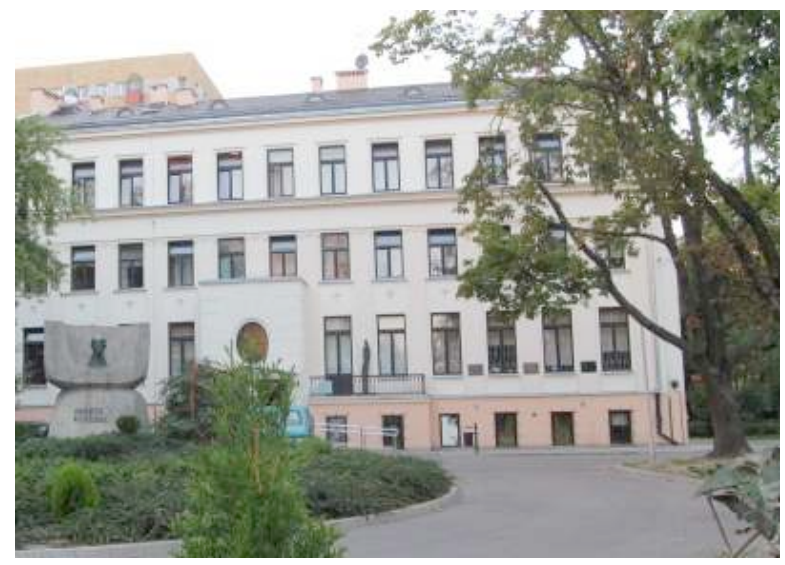

Maison des Orphelins de Janusz Korczak avec son monument (photo Izabella Zatorska) 


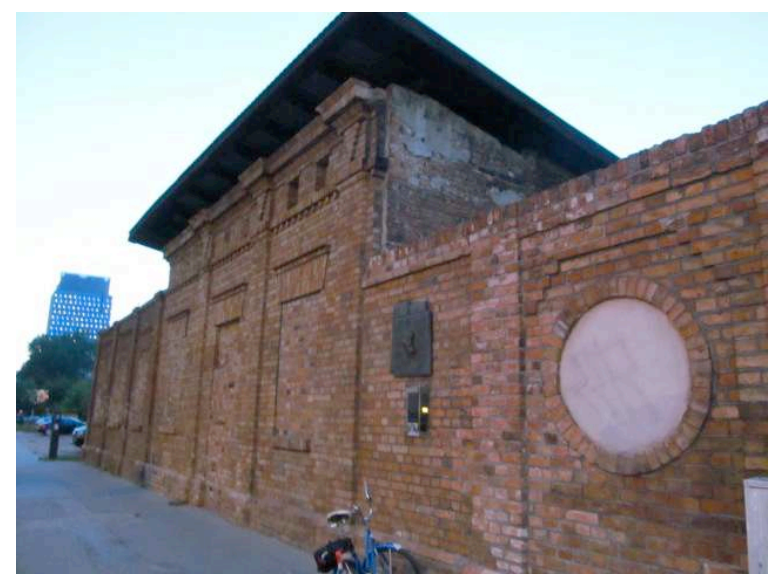

Mur d'enceinte du ghetto avec le plan accroché au mur à l'angle des rues Grzybowska et Żelazna (photo Izabella Zatorska)

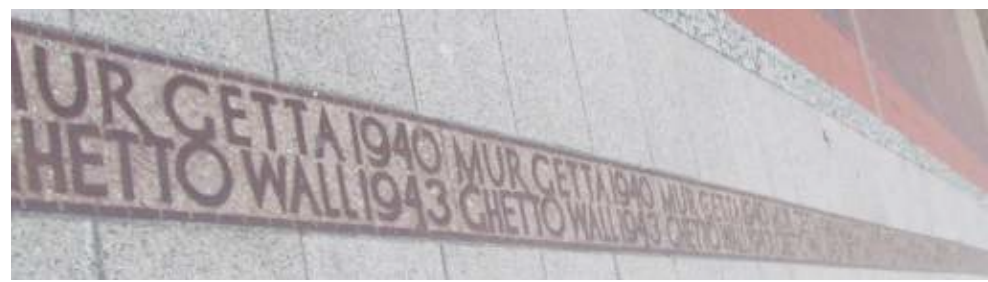

Marquage au sol du mur du ghetto (photo Izabella Zatorska)

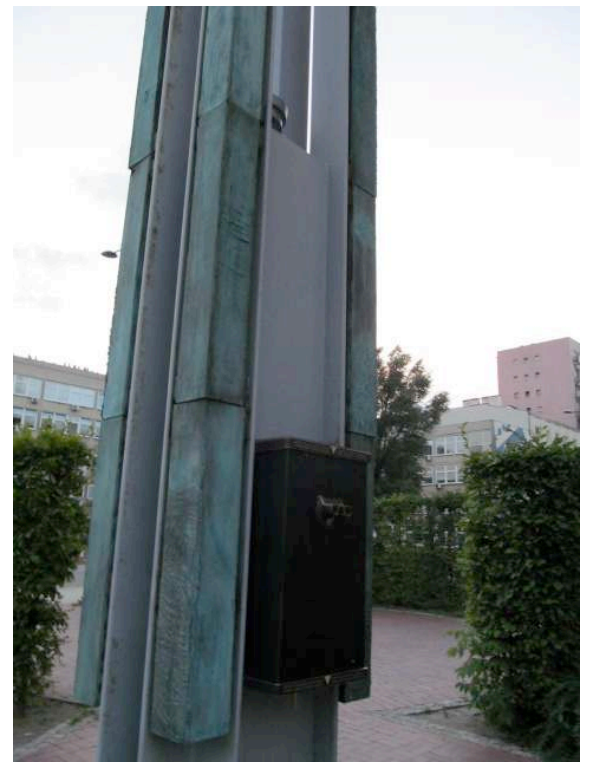

Pilier qui indique l'endroit où s'élevait la passerelle qui permettait la communication entre les deux ghettos (photo Izabella Zatorska) 